DOI: $10.34185 / 1991-7848.2019 .01 .09$

УДК 669.184.244.66

\author{
С.И. Семыкин, Т.С. Голуб, С.А. Дудченко, В.В. Вакульчук
}

\title{
ВЫСОКОТЕМПЕРАТУРНЫЕ ИССЛЕДОВАНИЯ ОСОБЕННОСТЕЙ ВЛИЯНИЯ НИЗКОВОЛЬТНОГО ПОТЕНЦИАЛА НА ПОВЕДЕНИЕ ШЛАКО-МЕТАЛЛИЧЕСКОЙ ВАННЫ ПРИ ПРОДУВКЕ СВЕРХУ
}

\begin{abstract}
Высокотемпературными исследованиями особенностей проявления влияния низковольтного потенцииала на конвертерную ванну подтверждены тенденции, выявленные на промышленных конвертерах по: влияния положительной полярности на фурми на повышение температуры ванны и ведущая роль характера процесса шлакообразования на величину силы тока в цепи фурма-ванна. Установлено переменный за ходом продувки характер подъема и осадки шлаковой фазы с противоположным направлением для двух полярностей потенциала. Выявлено, что вариант с положительной полярностью на фурме отличался промежуточным уровнем формируемых шлако-металлических брызг, несмотря на визуально наименьшее количество шлаковой фазы, а вариант с отрицательной полярностью - более ранним наведением шлака с наибольшим уровнем его подъема и с наименьшим количеством брызг. Установлено влияние низковольтного потенциала на снижение уровня потерь металла со шлаком: при отрицательной полярности в большей степени с корольками, а при положительной - с оксидами железа в шлаке.
\end{abstract}

Ключевые слова: высокотемпературная модель, кислородная продувка, шлакометаллическая ванна, низковольтный потенциал

\section{Постановка проблемы}

В настоящее время кислородно-конвертерный процесс является основным и наиболее экономичным способом производства стали. Несмотря на достаточно длительный период своего существования и всестороннего исследования его потенциал повышения технико-экономических показателей достаточно высокий, что придает актуальность исследованиям, направленным на использование этих резервов и решение главных задач - повышения эффективности производства и ресурсосбережение.

\section{Анализ последних исследований и постановка цели}

Многочисленные промышленные опыты в конвертерах 60-т, 160-т и 250-т в периоды освоения в ИЧМ НАНУ метода подвода низковольтных потенциалов к фурме и металлическому расплаву показали возможность улучшение ряда важных технологических показателей выплавки стали [1]. Целью данных исследований было выявление в лабораторных условиях причин и особенностей влияния внешнего

(c) Семыкин С.И., Голуб Т.С., Дудченко С.А., Вакульчук В.В., 2019 
низковольтного потенциала на шлако-металлическую ванну по ходу продувки металла в кислородных конвертерах.

В работе рассмотрены результаты лабораторных высокотемпературных исследований эффектов, возникающих, при прохождении электрического тока по электрической цепи: фурма- сталеплавильная ванна.

\section{Методика проведения экспериментов}

На лабораторной базе ДГТу была разработана и создана модельная установка (рис. 1) [2], на базе индукционной 160-т печи, которую дооборудовали системами: подачи кислорода через верхнюю фурму, отвода отходящих газов и электрической схемой подвода низковольтных потенциалов к фурме и конвертерной ванне.

$$
\begin{aligned}
& \text { 1-индцкционная печь, } \\
& 2 \text {-жидкий металл, } \\
& 3 \text { - шлак, } \\
& 4 \text { - продувочная фурма, } \\
& 5 \text { - источник тока, } \\
& 6 \text { - выпрямитель тока, } \\
& 7 \text { - медные подводы тока, } \\
& 8 \text { - контактный электрод, } \\
& 9 \text { - пускатель, } \\
& 10 \text { - сопротивления, } \\
& 11 \text { - регистрирующие приборы, } \\
& 12 \text { - редуктор, } \\
& 13 \text { - ротаметр, } \\
& 14 \text { - баллон с кислородом, } \\
& 15 \text { - цифровой манометр, } \\
& 16 \text { - видеокамера }
\end{aligned}
$$

Рисунгок 1 - Функциональная схема проведения опытов по высокотемпературному моделированию

До начала эксперимента в индукционной печи расплавляли 100-120 кг чугуна с содержанием углерода 4,2-3,2 \% масс. и нагревали до температуры $1450-1550^{\circ} \mathrm{C}$. После печь выключали, фурму разворачивали в сторону печи и опускали до рабочего положения порядка 25-30 калибров диаметра сопла над расплавом (величина, характерная для промышленных конвертеров). Для продувки применяли четырех сопловую фурму (диаметр сопла 1,7 мм, угол наклона к оси фурмы $14^{\circ}$ ). С началом подачи кислорода (чистотой порядка 99,2 \% при расходе 0,18 м³/мин) включали подачу напряжения на фурму и контактный электрод от низковольтного источника тока. Было проведено 6 опытных продувок по трем вариантам: без воздействий (вариант 1) и с подводом низковольтного потенциала отрицательной (вариант 2) и положительной (вариант 3) полярности к фурме (и соответственно противоположной полярности к контактному электроду). Длительность продувки металла была ограничена по причине недопустимости появления в открытом тигле индукционной 
печи заметного вспенивания шлака, что характерно для периода максимальной скорости процесса обезуглероживания металлического расплава. С целью повышения проводимости шлакового слоя плавки проводились с дополнительным вводом оборотного конвертерного шлака в количестве порядка $10 \%$.

Для выявления влияния низковольтного потенциала на процесс вспенивания шлака и подъем ванны в процессе продувки на ряде плавок после расплавления присадки оборотного шлака производили отключение/включение подаваемого к фурме и ванне напряжения.

Непрерывно, начиная с момента опускания фурмы в печь и до момента прекращения продувки, производилась регистрация на ПК ряда показателей: давления кислорода перед фурмой, силы тока в цепи фурма - расплав, а также производилась видеозапись подфурменной области с помощью закрепленной в штативе скоростной видеокамеры CASIO EXILIM EX F1 (частота записи 300 кадров в секунду).

\section{Изложение основного материала исследований}

Исследованиями в индукционной печи, в первую очередь, установлены визуальные различия в характере продувки без воздействий и при использовании отрицательной и положительной полярностей потенциала на фурме, которые впоследствии были проанализированы при покадровом просмотре видеоматериалов. На рис. 2 показаны особенности взаимодействия кислородных струй с металлическим расплавом по опытным вариантам, отражающие характерное влияние полярности низковольтного потенциала на процесс продувки в определенные периоды продувки плавки. Отмечено, что плавки, проводимые по варианту 1, в течение всей продувки отличались более медленным усвоением присаженной порции шлака и меньшим уровнем светимости подфурменной области. Визуально для продувок по варианту 1 было характерно наибольшее количество брызг капелек металла и шлака различных размеров, особенно на начальном этапе продувки, что отражает вероятность более высоких потерь металла вследствие его выноса.

Плавки, проведенные по варианту 2 , отличались визуально наибольшим уровнем подъема ванны, а значит и большим объемом формируемого шлака, что можно пояснить не только активным усвоением (растворением) присаженной порции оборотного шлака, но и дополнительным поступлением (выталкиванием) шлака из реакционных зон на всех этапах продувки. Кроме этого исследования показали, что отрицательной полярности на фурме по ходу продувки характерно формирование вязких пробивающих слой шлака всплесков в виде столбиков, поднимающихся на значительную высоту над шлаковым расплавом, и которые под влиянием поверхностных сил на каком-то этапе развития всплеска разрушались на капли с размерами, сопоставимыми с диаметром всплеска, и меньших размеров.

Установленный эффект, вероятно, можно пояснить особенностями процесса обезуглероживания металла при отрицательной полярности, влияние которой проявляется в активизации подшлакового «кипения» с образованием мелких 
пузырьков СО, сливающихся в более крупные образования, и, при определенной критической величине объема укрупненного пузыря, за счет сил Архимеда газ выталкивающиеся вверх, поднимая купол вязкого шлака на значительную высоту. Указанный эффект корреспондируется с результатами проведенных ранее исследований, указывающих на формирование при отрицательной полярности крупнопористых с большим количеством пор шлаков [3-4].

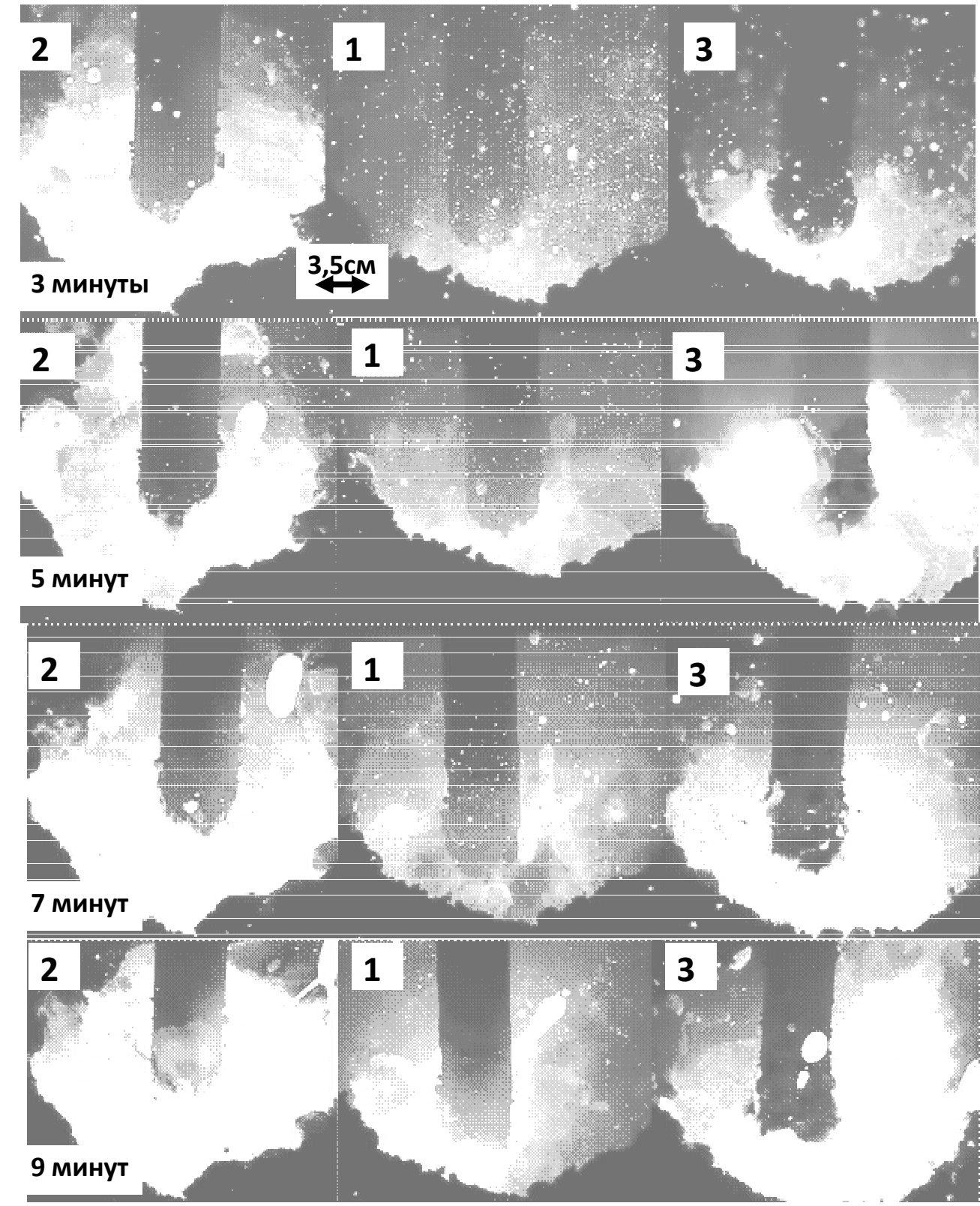

Рисунок 2 - Фрагменты видеозаписи продувки расплава чугуна через 4-х сопловый наконечник на различных минутах продувки, по опытным вариантам:

1 - без воздействий, 2 - отрицательная полярность на фурме, 3 - положительная полярность

Для плавок, проведенных по варианту 3, характерным было визуально наибольшая интенсивность свечения подфурменной зоны по ходу продувки, которая, по-видимому, отражает наибольший температурный уровень ванны в этом варианте. 
На данных продувках присаженная порция шлака активно растворялась и по ходу продувки шлаку было присуще активное «кипение» с формированием ярких вспышек - свищей на поверхности. Визуально продувки по варианту 3 отличались наименьшим количеством брызг.

По полученным видеозаписям путем посекундного анализа видеоматериала была произведена оценка уровня подъема шлако-металлической ванны по ходу продувки, результаты которой представлены на рис. 3. Выявлено, что по ходу продувки для всех опытных вариантов в данных лабораторных условиях уровень подъема ванны имел переменный характер, с достижением максимумов подъема на 6 минуте в варианте 1 и 3 и на 8 минуте в варианте 2. При этом наиболее высокие значения подъема уровня ванны соответствовали вариантам с подводом низковольтного потенциала, особенно в варианту с отрицательным потенциалом на фурме в течение практически всего времени продувки.

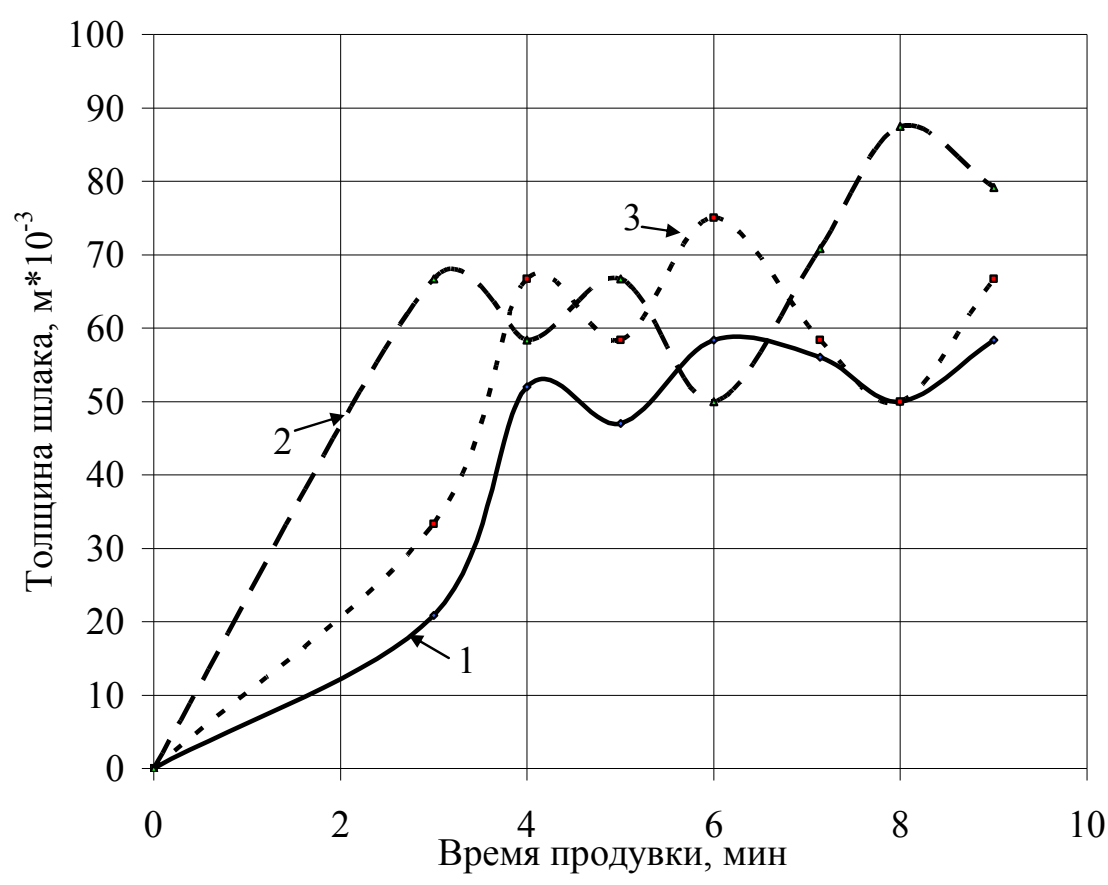

Рисунок 3 - Диаграмма изменения уровня подъема шлако-металлической ванны по ходу продувки по опытным вариантам: 1 - без воздействий,

2 - отрицательная полярность на фурме, 3 - положительная полярность

Установленные визуальные различия в поведении жидкой ванны по ходу продувки по опытным вариантам и различия в уровне подъема ванны связаны, как с особенностями воздействия подводимого потенциала той или иной полярности на протекание основных окислительно-восстановительных процессов по ходу продувки, так и с влиянием различной полярности на фурме на физические характеристики (поверхностное натяжение, кинематическая вязкость) самого шлакового расплава, описанные в работах [3-4].

Дополнительно на части экспериментов были проведены исследования особенности реакции отклика сталеплавильной ванны на кратковременное 
чередование операции включения/выключения потенциала продолжительностью по 34-35 секунд при различных вариантах подведения потенциала. Опыты были проведены в сопоставимые (для изучаемых опытных вариантов) периоды продувки. На рис. 4 приведены участки диаграмм изменения силы тока в цепи фурма- жидкая ванна в период проведения операции по включению/выключению потенциала по вариантам 2 и 3 соответственно (на рисунках время продувки обнулено относительно начала проведения операции включения/выключения потенциала).
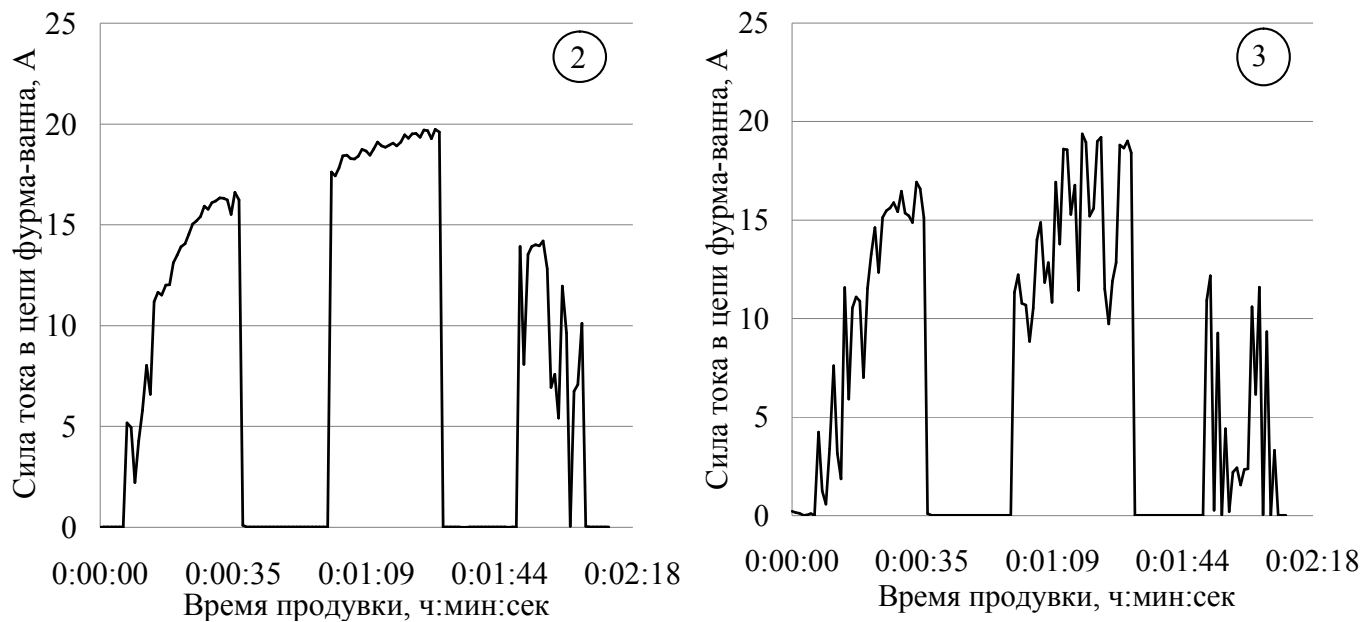

Рисунок 4 - Участки токовых диаграмм, записанные при чередовании операции по включению/выключению потенциала, по опытным вариантам с подводом низковольтного потенциала: 2 - отрицательная полярность на фурме, 3 - положительная полярность

Как описано в методике, для данных плавок было характерным добавление в самом начале продувки оборотного конвертерного шлака в количестве 10 \% от веса чугуна. Из диаграмм следует, что присадка шлака, содержащего окислы железа, повышает проводимость сталеплавильной ванны и позволяет получить силу тока в цепи фурма ванна сразу же после включения потенциала. При первом включении потенциала отрицательной полярности первоначально появились небольшие значения силы тока, которые затем увеличивались до максимальных значений, вероятно, по мере расплавления оборотного шлака. Это свидетельствует о том, что оборотный шлак активизирует процессы, на которые влияет отрицательная полярность потенциала, в частности накопление в шлаке оксидов железа, повышающих проводимость среды. При положительной полярности на фурме сила тока, подобно варианту с отрицательной полярностью, достигла своих наибольших значений плавно после включения потенциала. Это, по-видимому, обусловлено быстрым расплавлением оборотного шлака в силу развиваемых высоких температур в этом варианте с повышением проводимости ванны. Однако, в данном варианте также наблюдается анодное восстановление окислов железа из шлака, что приводит к снижению проводимости ванны, а, следовательно, и силы тока в цепи фурма - ванна, что проявляется в скачкообразном характере изменения силы тока.

При выключении потенциала с отрицательной полярностью на фурме визуально уровень ванны продолжал подниматься, что отражало интенсификацию процесса 
горения кремния, а при выключении потенциала с положительной полярностью на фурме отмечено увеличение высоты и яркости свечения факела над горловиной конвертера, что свидетельствовало о раннем начале окисления углерода, в период, когда еще должен окисляться кремний (в результате температура ванны продолжала повышаться).

При повторном включении потенциала обеих полярностей процесс формирования шлака продолжался, сопровождаясь увеличением силы тока. При отрицательной полярности сила тока плавно (без значительных колебаний) нарастала вплоть до момента отключения потенциала, что соответствовало накоплению шлака с подъемом ванны и обеспечением ровного и постоянного электрического контакта в цепи фурма - металлический расплав. При положительной полярности сила тока скачкообразно увеличивалась до максимальных для этого периода продувки значений, а затем также скачкообразно начала снижаться, что соответствовало сначала подъему ванны за счет развития процесса окисления углерода после его включения, а затем восстановлению железа из окислов с ухудшением проводимости ванны, a, следовательно, и уменьшению силы тока. То есть условия для шлакообразования с точки зрения обеспечения электрического контакта между фурмой и ванной были менее благоприятными в вариате 3.

Визуально также отмечено, что выключение низковольтного потенциала в варианте 2 на 20 секунд не вызвало снижения уровня подъема ванны, и сила тока после включения продолжила повышаться до максимальных значений за счет увеличения поверхности соприкосновения шлако-металлической фазы с корпусом фурмы. Это, кроме приведенных выше объяснений, свидетельствует о том, что результат направленного активизирующего действия низковольтного потенциала данной полярности на шлакообразование и протекание основных процессов продолжался еще некоторое время (5-15 секунд) после разрыва внешней цепи $[3,4]$.

В варианте 3 первое отключение и повторное включение потенциала несколько ухудшило контакт, о чем свидетельствует более низкий по сравнению с вариантом 2 уровень подъема силы тока.

Последующее повторное выключение и третье включение потенциала в обоих вариантах значительно осадило уровень ванны, что привело к снижению максимального уровня силы тока в цепи фурма - ванна (с 19 А до 14,5 А в варианте 2 и с 17 до 12,5 А в варианте 3). Кроме того, в варианте 2 это привело к значительным колебаниям зарегистрированных значений силы тока, а в варианте 3 - к снижению уровня ванны и значительному ухудшению контакта в цепи.

Следовательно, проведенным дополнительным исследованием реакции шлакометаллической ванны на операцию включения/выклбючения потенциала было установлено наличие некоторого периода последействия низковольтного потенциала после разрыва электрической цепи, особенно при отрицательной полярности на фурме. Также получыеные результаты свидетельсвуют о наличии возможности направленного воздействия (корректировки) на процесс подъема ванны без ухудшения условий шлакообразования путем осуществления данной операции включения/выключения. 
Химический анализ проб металла, а также уровень температуры ванны, полученные до и после проведения продувок, представлены в таблице 1. Выявлено, что после продувки кислородом наибольшее повышение температуры обеспечивалось в варианте 3, тогда как наименьшее повышение температуры соответствовало продувкам по варианту 1. Анализ изменения уровня содержания основных компонентов металла за время продувки показал, что для плавок, проведенных по варианту 2, отмечен меньший уровень окисления углерода, но больший уровень окисления кремния, чем в варианте 1. В то время как в варианте 3 отмечен противоположный характер влияния на окисление примесей. Полученные результаты корреспондируются с результатами проведенных ранее работ [3,4].

Таблица 1

Средний уровень полученных показателей лабораторных продувок

\begin{tabular}{|c|c|c|c|c|}
\hline \multirow{2}{*}{$\begin{array}{l}\text { № } \\
\text { п.П. }\end{array}$} & \multirow[t]{2}{*}{ Параметры продувки } & \multicolumn{3}{|c|}{ Опытные варианты } \\
\hline & & Вариант 1 & Вариант 2 & Вариант 3 \\
\hline 1 & Температура чугуна, ${ }^{\circ} \mathrm{C}$ & 1478 & 1450 & 1410 \\
\hline 2 & Температура металла, ${ }^{\circ} \mathrm{C}$ & 1630 & 1615 & 1638 \\
\hline 3 & Прирост температуры за продувку, ${ }^{\circ} \mathrm{C}$ & 152 & 165 & 228 \\
\hline \multirow[t]{3}{*}{4} & Хим.состав чугуна, \%масс: & & & \\
\hline & -углерод & 4,32 & 4,42 & 4,26 \\
\hline & -кремний & 0,94 & 0,97 & 0,90 \\
\hline \multirow[t]{3}{*}{5} & Хим.состав металла, \%масс & & & \\
\hline & - углерод & 1,42 & 1,63 & 1,20 \\
\hline & -кремний & 0,010 & 0,012 & 0,028 \\
\hline 6 & $\begin{array}{l}\text { Удельное количество окислов железа } \\
\text { в шлаке"), кг/т стали }\end{array}$ & 19,30 & 23,95 & 15,10 \\
\hline 7 & $\begin{array}{lcr}\text { Удельное } & \text { количество } & \mathrm{Fe} \\
\text { металлаического в шлаке, кг/т стали }\end{array}$ & 10,74 & 4,84 & 10,94 \\
\hline 8 & Итого потери металла, кг/т стали & 30,04 & $28,79(-1,25)^{*}$ & $26,04(-4,00)$ \\
\hline
\end{tabular}

$\mathrm{GFeO}=$ Gшлак·(FeO)·1000/100·Gсталь

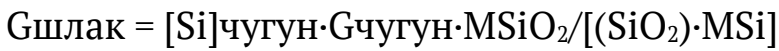

где GFeO удельный вес $\mathrm{FeO}$ в шлаке, (кг/т стали), Gшлак, Gчугун, и Gсталь где вес шлака, чугуна и стали, соответственно (кг), (FeO) и $\left(\mathrm{SiO}_{2}\right)$ весовое содержание компонентов в шлаке (масс.\%), [Si]чугун содержание кремния в чугуне (масс.\%), и $\mathrm{MSiO}_{2}$ и $\mathrm{MSi}$ молярные массы соответствующих компонентов (кг/моль).

*:) приведено отклонение от варианта 1

Также полученные результаты свидетельствуют о том, что обе полярности в целом оказывают влияние на снижение потерь металла со шлаком: на 1,25 кг/т стали в варианте 2 и на 4,00 кг/т стали в варианте 3. При этом при отрицательной полярности в большей степени уменьшаются потери с железом в виде корольков (Fе металлическое): на 5,9 кг/т стали, а при положительной - с окислами железа на 4,2 кг/т стали, безвозвратно теряемыми со шлаком. 


\section{Выводы}

Высокотемпературными экспериментами подтверждены тенденции, выявленные на промышленных конвертерах: по ранжировке вариантов по силе влияния их на теплосодержание ванны и по ведущей роли характера процесса шлакообразования на величину силы тока в цепи фурма- ванна.

Анализом видеоматериалов установлен переменный по ходу продувки плавки характер подъема и оседания шлаковой фазы, причем изменение этих параметров имеет противоположное направление для двух полярностей подводимого потенциала. Отмечено, что лабораторные продувки отличались по яркости свечения зоны взаимодействия кислородной струи со сталеплавильной ванной: самое яркое свечение подфурменной зоны наблюдалось в варианте 3, самое слабое свечение - в варианте 1 . Также отмечено, что вариант 3 отличался промежуточным уровнем формируемых брызг металла и шлака, несмотря на наименьшее из числа изученных вариантов визуальное количество шлаковой фазы, а вариант 2 - более ранним наведением жидкоподвижного шлака с наибольшим уровнем его подъема, что послужило причиной уменьшения брызг металла.

Выявлен специфический эффект по влиянию отрицательной полярности на конвертерную ванну с образованием локальных всплесков в виде столбиков. Предложен вероятный механизм их появления.

Установлено влияние подводимого низковольтного потенциала на снижение уровня потерь метала со шлаком: при отрицательной полярности в большей мере с корольками, а при положительной - с окислами железа в шлаке.

\section{ЛИТЕРАТУРА}

1. Семыкин С.И. Применение электрического воздействия малой удельной мощности при кислородно-конвертерной плавке стали / С.И. Семыкин, В.Ф. Поляков // Сталь.2014.- №9.- С.12-16;

2. Чернятевич А.Г. Высокотемпературное моделирование кислородно-конвертерного процесса /А.Г. Чернятевич // Известия ВУЗов. Черная металлургия.- 1991.- № 12.C. 16-18;

3. Семыкин С.И. Исследование особенностей влияния низковольтного потенциала на процессы рафинирования металла в кислородном конвертере/ С.И. Семыкин, Т. С. Кияшко, Е.В. Семыкина// Металл и литье Украины.- 2011.- №7.- С.29-33;

4.Семыкина Т. С. Влияние полярности налагаемого на конвертерную ванну электрического потенциала на состояние и химический состав шлакового расплава / Т. С. Семыкина, С. И. Семыкин // Фундаментальные и прикладные проблемы черной металлургии. - 2008. - выпуск 15. - С.125 - 129.

\section{REFFERENCES}

1. Semykin S.I., Poliakov V.F. Primenenie elektricheskogo vozdeystviya maloy udelnoy moshnosti pri kislorodno-konverternoy plavke stali [The use of electrical low powered influences at the oxygen-converter steel smelting], Stal', 2014, no.9, P. 12-16. 
2. Cherniatevich A.G., Visokotemperaturnoe modelirovanie kislorodno-konverternogo processa [High temperature modeling of BOF process], Izvestiya VUZov, Ch.M., 1991, no. 12, P. 16-18.

3. Semykin S.I., Kiiashko T.S., Semykina E.V., Issledovaniye osobennostey vliyaniya nizkovoltnogo potentsiala na protsessy rafinirovaniya metalla $\mathrm{v}$ kislorodnom konvertere [Research of features of influence of low voltage potential on the metal refining process in the basic oxygen furnace], Metall i lit'ye Ukrainy, 2011, no. 7, P. 29-33.

4. T. S. Semykina, S.I. Semykin Vliyanie poljarnosti nalagaemogo na konverternuju vannu elektricheskogo potentsiala na sostojanie i himicheskij sostav shlakovogo rasplava [Influence of the polarity of the imposed on the converter bath electric potential on the state and chemical composition of the slag melt], Fundamentalnyje i prikladnije problemy chernoj metallurgii, 2008, no.15, P. 125-129.

Received 14.01.19

\section{HIGH TEMPERATURE RESEARCH OF THE FEATURES OF THE LOW-VOLTAGE POTENTIAL INFLUENCE ON THE BEHAVIOR OF THE SLAG-METAL BATH AT TOP BLOWING}

Despite the long period of existence and comprehensive research, the oxygenconverter process has high potential for improving technical and economic indicators, which makes it relevant for studies aimed at solving problems of increasing production efficiency and resource saving.

Numerous industrial experiments in 60-ton, 160-ton and 250-ton converters during the periods of mastering the method of low-voltage potentials application to the lance and metal melt, designed in ISI NASU, showed the possibility of improving a number of important technological parameters of steel smelting.

The paper considers the results of laboratory high-temperature researches on oxygen converter model with top blowing of effects, arising when an electric current passes through an electrical circuit a lance-steelmaking bath at low-voltage potential application of negative or positive polarity to the lance and opposite polarity to the bottom contact electrode in comparison with heats, conducted without electric influence.

The trends revealed in industrial converters were confirmed: according to the effect of positive polarity on the lance on the temperature of the bath and on the leading role of the character and intensity of the slag formation process on the level of the current in the chain lance- converter bath. There was also a difference in the brightness of the zone of interaction between the oxygen jet and the slag-metal melt according to the studied options, corresponding to the heat content of the bath: the brightest glow of the sublance zone was observed at the application of positive polarity to the lance, and the weakest glow on comparative heats.

By analyzing the video materials, the alternating character of the foaming and gone of the slag phase during the course of the blowing was revealed, that characterized by the opposite direction for the two polarities of the applied potential. It was also noted that the heats carried out with the positive polarity of the potential on the lance differed by a low level of formed splashes of metal and slag, despite the smallest visual amount of the slag phase. And the smallest level of metal splashes was visually noted in the option of application of negative polarity to the lance. It was also revealed that blowings with negative 
polarity application to the lance differed by earlier liquid slag formation with the highest level of its rise.

A specific effect was revealed on the influence of the potential polarity on the surface of the slag phase compared with the option without effects: the formation of local high bursts in the form of "columns" at negative polarity on the lance and "viscous" boiling with an intense output of $\mathrm{CO}$ torches on the surface at a positive polarity on the lance.

The effect of the low-voltage potential application on reducing the level of metal losses with slag was established: with negative polarity at the lance with the metal drops on $5.9 \mathrm{~kg} / \mathrm{t}$ of steel, and with positive polarity, with iron oxides in the slag on $4.2 \mathrm{~kg} / \mathrm{t}$ of steel.

Keywords: high-temperature model, oxygen blowing, slag-metal bath, low-voltage potential.

\section{ВИСОКОТЕМПЕРАТУРНІ ДОСЛІДЖЕННЯ ОСОБЛИВОСТЕЙ ВПЛИВУ НИЗЬКОВОЛЬТНОГО ПОТЕНЦІАЛУ НА ПОВЕДІНКУ ШЛАКО-МЕТАЛЕВОЇ ВАННИ ПРИ ВЕРХНІЙ ПРОДУВЦІ}

Високотемпературними дослідженнями особливостей прояву впливу низьковольтного потенціалу на конвертерну ванну підтверджені тенденції, виявлені на промислових конвертерах щодо: впливу позитивної полярності на фурмі на підвищення температури ванни та провідна роль характеру процесу шлакоутворення на величину сили струму в ланцюзі фурма- ванна. Встановлено змінний за ходом продувки характер підйому і осідання шлакової фази з протилежним напрямком для двох полярностей потенціалу. Виявлено, що варіант з позитивною полярністю на фурмі відрізнявся проміжним рівнем формованих шлако-металевих бризок, незважаючи на візуально найменшу кількість шлакової фази, а варіант 3 негативною полярністю - більш раннім наведенням шлаку з найбільшим рівнем його підйому і 3 найменшою кількістю бризок. Встановлено вплив низьковольтного потенціалу на зниження рівня втрат металу зі шлаком: при негативній полярності в більшій мірі 3 корольками, а при позитивній - з оксидами заліза в шлаку.

Ключові слова: високотемпературна модель, киснева продувка, шлако-металева ванна, низьковольтний потенціал

Семикін Сергій Іванович - с.н.с., канд. техн. наук, Інститут чорної металургії ім. 3.I. Некрасова НАН України.

Semykin Sergey - PhD, senior researcher, Iron and Steel Institute of Z.I. Nekrasov of National academy of science of Ukraine.

Голуб Тетяна Сергіївна - н.с., канд. техн. наук, Інститут чорної металургії ім. 3.I. Некрасова НАН України.

Golub Tatiana - PhD, researcher, Iron and Steel Institute of Z.I. Nekrasov of National academy of science of Ukraine.

Дудченко Сергій Олександрович - н.с., Інститут чорної металургії iм. 3.І. Некрасова НАН України.

Dudchenko Sergiy - researcher, Iron and Steel Institute of Z.I. Nekrasov of National academy of science of Ukraine.

Вакульчук Володимир Вікторович - м.н.с., Інститут чорної металургії ім. 3.І. Некрасова НАН України.

Vakulchuk Volodymyr - junior researcher, Iron and Steel Institute of Z.I. Nekrasov of National academy of science of Ukraine. 